\title{
High grade carcinoma ex pleomorphic adenoma of parotid gland: a case report
}

\author{
Ji-Kwan Kim¹, Moon-Young Kim¹, Seung-Kyu Choi ${ }^{2}$ \\ ${ }^{1}$ Department of Oral and Maxillofacial Surgery, College of Dentistry, Dankook University, \\ ${ }^{2}$ Department of Pathology, Dankook University College of Medicine, Cheonan, Korea
}

\begin{abstract}
J Korean Assoc Oral Maxillofac Surg 2020;46:348-352)
Pleomorphic adenoma is the most prevalent benign tumor of the parotid gland, and shows potential malignancy. Carcinoma ex pleomorphic adenoma (CXPA) can occur in 3\%-15\% of pleomorphic adenoma cases. Owing to its clinical similarity to benign tumors, critical information related to CXPA can be easily overlooked, leading to frequent misdiagnosis of the condition. In this article, we report a rare case of CXPA found in the 55-year-old male patient with characteristic clinical, radiographic, and histological features, and subsequent treatment.
\end{abstract}

Key words: Pleomorphic adenoma, Carcinoma, Cancer of the head, Parotid gland

[paper submitted 2020. 1. 3 / revised 1st 2020. 3. 16, 2nd 2020. 4. 1 / accepted 2020. 4. 2]

\section{Introduction}

Pleomorphic adenoma $(\mathrm{PA})$ is the most prevalent benign tumor of the parotid gland and shows potential malignancy. According to the histological classification published in 2005 by the World Health Organization ${ }^{1}$, PA can be transformed into three types of malignancies: carcinoma ex PA, carcinosarcoma, and metastasizing PA. Most common in the parotid gland and then in the submandibular gland, carcinoma ex PA (CXPA) occurs in $3 \%-15 \%$ of cases of $\mathrm{PA}^{2}$. In this article, we report a rare case of CXPA in a 55-year-old male who had characteristic clinical, radiographic, and histological features and describe the subsequent treatment.

\section{Case Report}

A 55-year-old male visited Dankook University Dental

\footnotetext{
Moon-Young Kim

Department of Oral and Maxillofacial Surgery, College of Dentistry, Dankook University, 119 Dandae-ro, Dongnam-gu, Cheonan 31116, Korea TEL: +82-41-550-0271 FAX: +82-41-551-8988

E-mail: rechare@dankook.ac.kr

ORCID: https://orcid.org/0000-0001-9596-7481

(c) This is an open-access article distributed under the terms of the Creative Commons Attribution Non-Commercial License (http://creativecommons.org/ licenses/by-nc/4.0/), which permits unrestricted non-commercial use, distribution, and reproduction in any medium, provided the original work is properly cited.

Copyright (C) 2020 The Korean Association of Oral and Maxillofacial Surgeons. All rights reserved.
}

Hospital with the complaint of right facial swelling that began 10 years previously but had dramatically worsened over the last 6 months. He claimed to neither drink alcohol nor smoke, and he suffered no concomitant medical conditions.

Initial clinical assessment of the patient revealed swelling and induration of the right parotid gland. However, no specific signs or symptoms of facial nerve derangement, skin lesion, or inflammation were found. Preoperative magnetic resonance (MR) images revealed a mass in the right parotid area, measuring approximately $7 \mathrm{~cm}$.(Fig. 1) The mass was initially diagnosed as a benign tumor of the superficial lobe of the right parotid gland, and superficial parotidectomy under general anesthesia was planned.

Although we expected the lesion to be limited to the superficial lobe, it was found to extend to the deep lobe during surgery, so total parotidectomy was performed. The facial nerve was preserved as no symptoms or conditions related to the nerve, such as facial nerve palsy, had been observed prior to surgery.(Fig. 2)

Biopsy results revealed an irregular ductal structure along with cells of various sizes and necrosis at low magnification, representing high-grade carcinoma.(Fig. 3) The hyalinized region of a previous PA (Fig. 4) that had existed before its transformation into carcinoma was observed on high-magnification images. No evidence of lymphovascular or perineural invasion or margin involvement was found. 

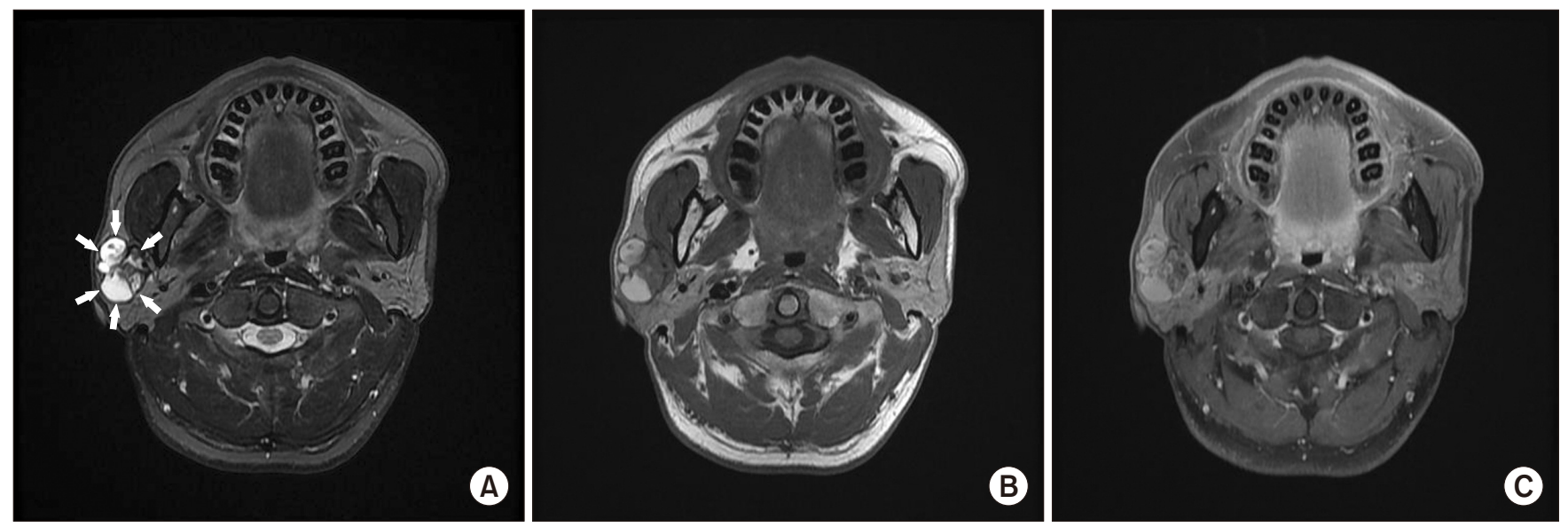

Fig. 1. Magnetic resonance (MR) images. MR images showing a $7 \mathrm{~cm}$ sized, well-circumscribed, multiseptated solid and cystic mass with variable signal which located in the right parotid gland. A. T2-weighted image. Boundary of mass is marked with arrows. B. T1-weighted image. C. Enhanced T1-weighted image.

Ji-Kwan Kim et al: High grade carcinoma ex pleomorphic adenoma of parotid gland: a case report. J Korean Assoc Oral Maxillofac Surg 2020
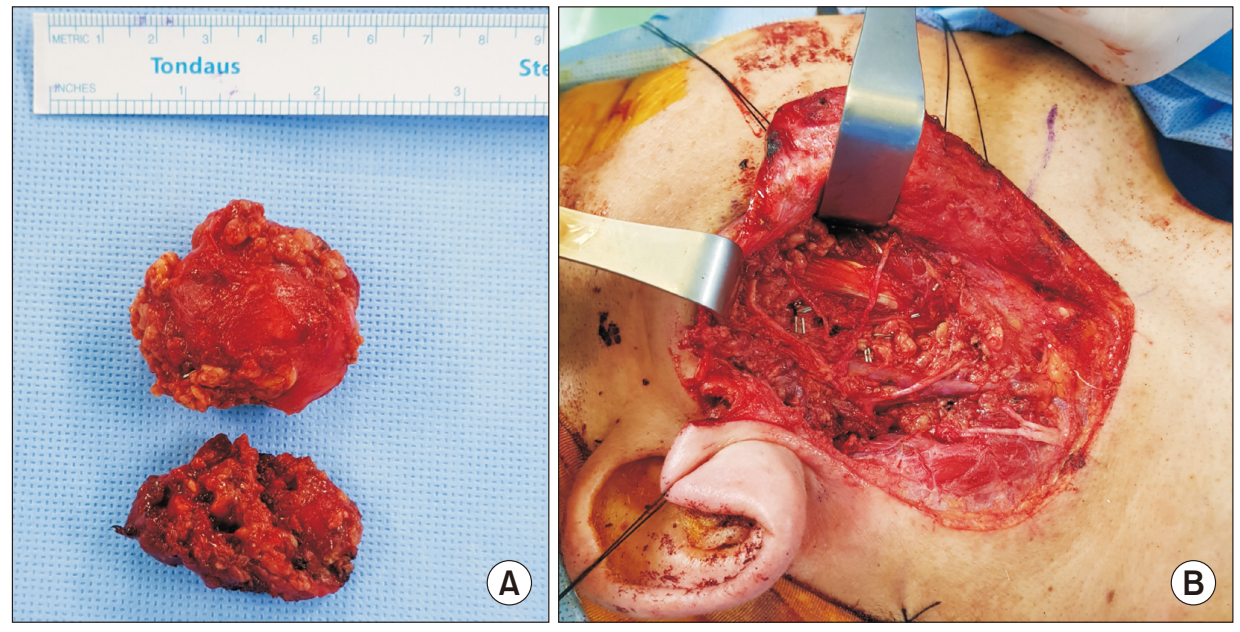

Fig. 2. A. Resected superficial and deep lobe of parotid gland. The top is superficial lobe, and the bottom is deep lobe. B. Parotid bed following total parotidectomy.

Ji-Kwan Kim et al: High grade carcinoma ex pleomorphic adenoma of parotid gland: a case report. $J$ Korean Assoc Oral Maxillofac Surg 2020
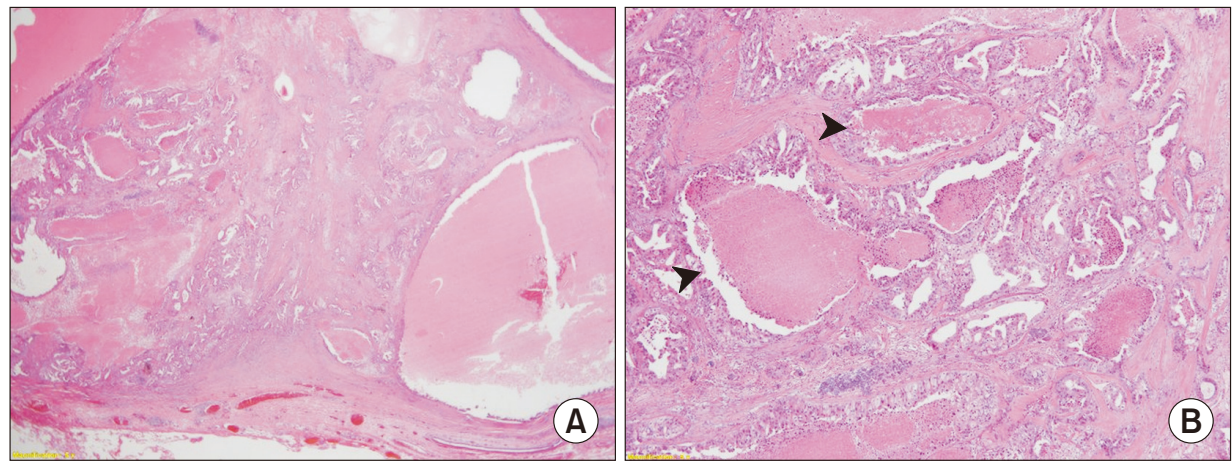

Fig. 3. A. Low-power view revealed well circumscribed high-grade carcinoma showing variable sized cysts and irregular ductal structures with marked necrosis (H\&E staining, $\times 20)$. B. The ductal carcinoma component exhibited marked cytologic atypia and comedo necrosis (arrowheads) (H\&E staining, $\times 40)$.

Ji-Kwan Kim et al: High grade carcinoma ex pleomorphic adenoma of parotid gland: a case report. $J$ Korean Assoc Oral Maxillofac Surg 2020

Based on clinical, radiological, and pathological findings, the patient was diagnosed with high-grade CXPA Stage II (pT2N0M0) according to the American Joint Committee on Cancer (AJCC) Cancer Staging Manual (8th edition).
Because the boundary of the tumor was uncertain and the histological examination showed high-grade carcinoma, the patient underwent postoperative radiotherapy. Seven trials of radiotherapy were performed from 400 to 6,000 cGy. 

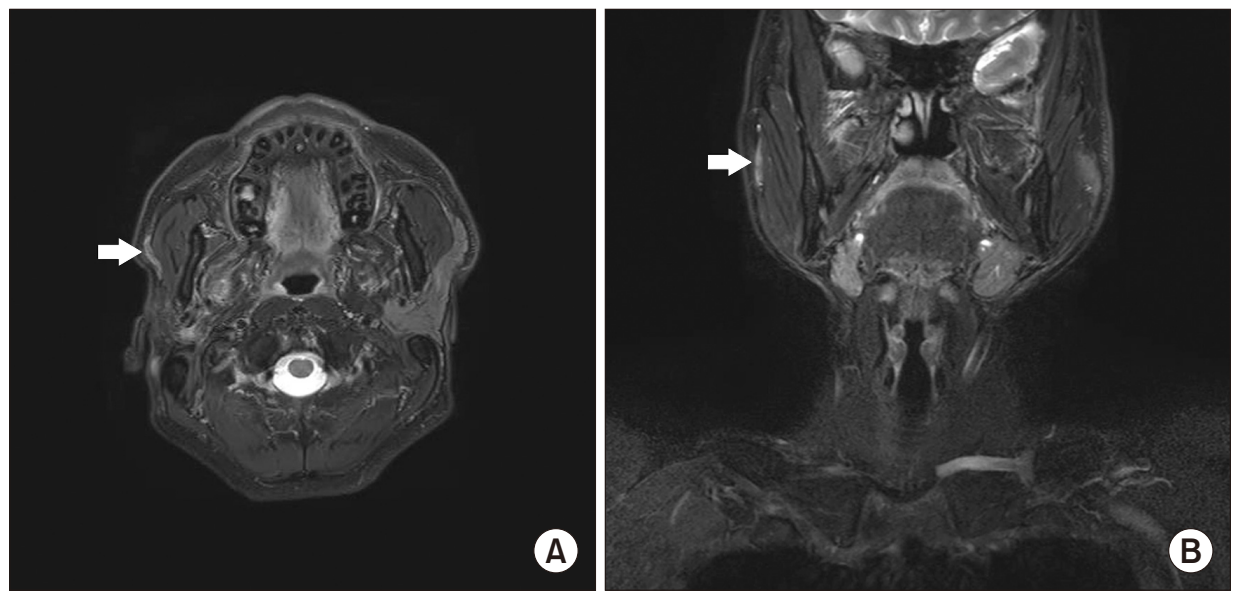

Fig. 5. Postoperative magnetic resonance (MR) images. A. Axial T2-weighted MR image. B. Coronal T2-weighted image. Subtle high signal on operation site showing postoperative change (arrows).

Ji-Kwan Kim et al: High grade carcinoma ex pleomorphic adenoma of parotid gland: a case report. $J$ Korean Assoc Oral Maxillofac Surg 2020

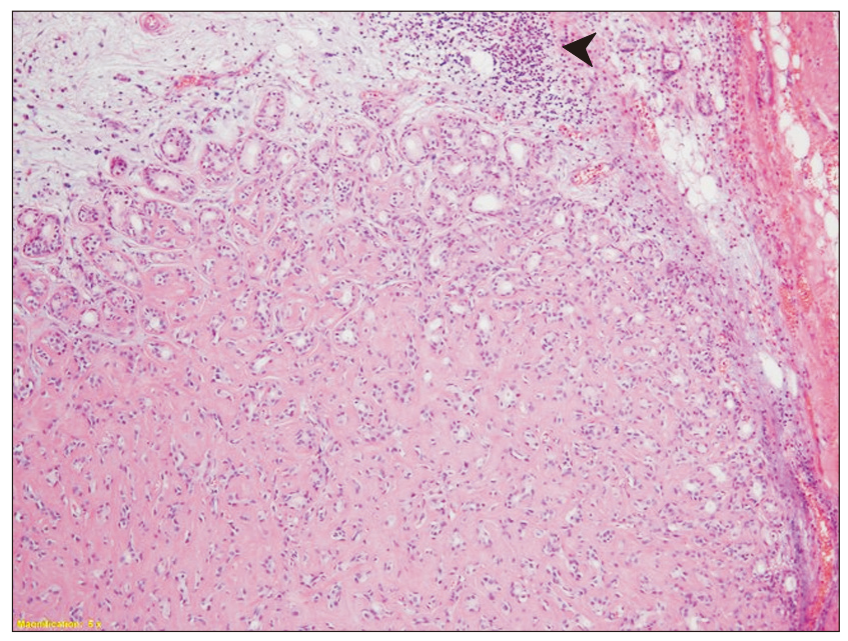

Fig. 4. Small portion of the tumor showed hyalinized area suggestive of pre-existing pleomorphic adenoma (arrowhead) (H\&E staining, $\times 100)$.

Ji-Kwan Kim et al: High grade carcinoma ex pleomorphic adenoma of parotid gland: a case report. J Korean Assoc Oral Maxillofac Surg 2020

The follow-up radiographs at 7 months and 13 months after termination of therapy demonstrated no signs of recurrence, metastases, or lymphadenopathy.(Fig. 5)

\section{Discussion}

Owing to its clinical similarity to benign tumors, CXPA can be easily overlooked, leading to frequent misdiagnosis of the condition ${ }^{3}$. The typical clinical presentation of CXPA is a longstanding history of PA and a sudden period of rapid growth ${ }^{4}$. In addition, the incidence of malignant transformation is related to the duration of PA. According to Seifert ${ }^{5}$, the risk of malignant transformation is only about $1.5 \%$ for a duration $<5$ years but increases to $9.5 \%$ for a duration $>15$ years. CXPA can be attached to surrounding structures and can results in skin ulcers and mouth opening restrictions. In more severe cases in which the tumor expands to the facial nerve, facial nerve weakness or paralysis may also occur ${ }^{6}$.

As CXPA is aggressive and infiltrating, it typically presents as an irregular mass extending into the gland parenchyma and beyond on radiographs. A heterogenous signal due to hemorrhage, necrosis, and calcification can be found on T1weighted MR images. Kato et al. ${ }^{7}$ suggested inclusion of diffusion-weighted and apparent diffusion coefficient (ADC) mapping imaging in MR imaging protocols of the salivary gland to facilitate differentiation of salivary gland tumors. The ADC values of CXPA are lower than those of PA, indicating hypercellularity.

Histopathologic subtypes of CXPA include adenocarcinoma NOS, salivary duct carcinoma, adenosquamous carcinoma, adenoid cystic carcinoma, and myoepithelial carcinoma. Tortoledo et al. ${ }^{8}$ subclassified 37 cases of CXPA according to histopathological characteristics, yielding 13 ductal, 10 undifferentiated, 9 terminal duct, and 3 myoepithelial subtypes, with two cases that could not be classified owing to the small size of the surgical specimen. However, a similar study by Lewis et al. ${ }^{9}$ showed different results, with most tumors classified as adenocarcinoma NOS ( 31 of 70), followed by salivary duct carcinoma (24 of 70).

Also, based on the presence and extent of invasion of the carcinomatous component outside the fibrous capsule, CXPA can be subdivided into non-invasive CXPA, minimally invasive CXPA, and invasive $\mathrm{CXPA}^{10}$. The carcinoma component in non-invasive CXPA is confined to the well-defined fibrous capsule. When the malignant component of CXPA invades less than $1.5 \mathrm{~mm}$ into the extracapsular tissue, it is classified as minimally invasive CXPA. Invasive CXPA is defined as greater than $1.5 \mathrm{~mm}$ invasion by the malignant component 
into the extracapsular tissue.

Superficial parotidectomy is the surgical treatment of choice for intracapsular or minimally invasive CXPA that is limited to the superficial lobe of the parotid gland ${ }^{6}$. However, total parotidectomy is indicated for more invasive and advanced cases. If the facial nerve is infiltrated by the tumor, facial nerve resection must be performed in conjunction with radical parotidectomy involving both the deep and superficial lobes of the parotid gland ${ }^{11}$. Concurrent neck dissection may be necessary when evidence of metastases is present among the cervical lymph nodes. Postoperative radiotherapy is indicated for patients with high-grade disease, questionable resection adequacy at the time of surgery, and lymph node or peri-neural invasion.

Two radiation techniques are commonly used for treating the parotid bed: one uses ipsilateral anterior and posterior oblique beams, and the other uses a mixed beam technique with a combination of photons and electrons. According to a report by Chen et al. ${ }^{12}$, radiation treatment for patients with CXPA was administered by continuous-course radiation with once-per-day treatment using conventional fractionation. The median radiation dose was $60 \mathrm{~Gy}$ (range, 45-71 Gy) and was chosen at the discretion of the treating radiation oncologist. They reported that addition of postoperative radiotherapy improved locoregional control for CXPA compared with surgery alone. The 3-year and 5-year overall survival rates for patients treated with surgery and postoperative radiation whose pathologic lymph node status was negative or unknown at the time of treatment were $82 \%$ and $71 \%$, respectively, compared with $76 \%$ and $52 \%$ for those treated without postoperative radiation.

The prognosis of CXPA is based on pathological staging parameters such as level of invasion, lymph node involvement, and local or distant metastasis ${ }^{13,14}$. Tumor size and grade can also be predictive of prognosis for invasive CXPA. Survival rates can be optimized via accurate diagnosis and subsequent aggressive surgical and radiological management.

In conclusion, preoperative identification of CXPA can be difficult, and the condition is associated with a worse survival rate compared to that of most other salivary gland malignancies. Therefore, accurate diagnosis through meticulous history taking, clinical assessment, and radiologic examination is needed to optimize treatment outcomes and survival.

\section{ORCID}

\author{
Ji-Kwan Kim, https://orcid.org/0000-0002-9354-6293 \\ Moon-Young Kim, https://orcid.org/0000-0001-9596-7481 \\ Seung-Kyu Choi, https://orcid.org/0000-0002-7508-6123
}

\section{Authors' Contributions}

M.Y.K. and J.K.K. wrote the manuscript. S.K.C. participated in data collection and helped to draft the manuscript. All authors read and approved the final manuscript.

\section{Consent for Publishing Photographs}

Written informed consent was obtained from the patients for publication of this article and accompanying images.

\section{Conflict of Interest}

No potential conflict of interest relevant to this article was reported.

\section{References}

1. Gnepp DR, Brandwein-Gensler MS, El-Naggar AK, Nagao T. Carcinoma ex pleomorphic adenoma. In: Barnes L, Eveson JW, Reichart P, Sidransky D, eds. World Health Organization classification of tumours. Pathology and genetics of head and neck tumours. Lyon: IARC Press; 2005:242-3.

2. Spiro RH, Huvos AG, Strong EW. Malignant mixed tumor of salivary origin: a clinicopathologic study of 146 cases. Cancer 1977;39:388-96. https://doi.org/10.1002/10970142(197702)39:2<388::aid-cncr2820390204>3.0.co;2-d

3. Antony J, Gopalan V, Smith RA, Lam AK. Carcinoma ex pleomorphic adenoma: a comprehensive review of clinical, pathological and molecular data. Head Neck Pathol 2012;6:1-9. https://doi. org/10.1007/s12105-011-0281-z

4. Beahrs OH, Woolner LB, Kirklin JW, Devine KD. Carcinomatous transformation of mixed tumors of the parotid gland. AMA Arch Surg 1957;75:605-13; discussion 613-4. https://doi.org/10.1001/ archsurg.1957.01280160115015

5. Seifert G. Histopathology of malignant salivary gland tumours. Eur J Cancer B Oral Oncol 1992;28B:49-56. https://doi. org/10.1016/0964-1955(92)90013-q

6. Olsen KD, Lewis JE. Carcinoma ex pleomorphic adenoma: a clinicopathologic review. Head Neck 2001;23:705-12. https://doi. org/10.1002/hed.1100

7. Kato H, Kanematsu M, Mizuta K, Ito Y, Hirose Y. Carcinoma ex pleomorphic adenoma of the parotid gland: radiologic-pathologic correlation with MR imaging including diffusion-weighted imaging. AJNR Am J Neuroradiol 2008;29:865-7. https://doi. org/10.3174/ajnr.A0974

8. Tortoledo ME, Luna MA, Batsakis JG. Carcinomas ex pleomorphic adenoma and malignant mixed tumors. Histomorphologic indexes. Arch Otolaryngol 1984;110:172-6. https://doi.org/10.1001/ archotol.1984.00800290036008 
9. Lewis JE, Olsen KD, Sebo TJ. Carcinoma ex pleomorphic adenoma: pathologic analysis of 73 cases. Hum Pathol 2001;32:596-604. https://doi.org/10.1053/hupa.2001.25000

10. Altemani A, Martins MT, Freitas L, Soares F, Araújo NS, Araújo VC. Carcinoma ex pleomorphic adenoma (CXPA): immunoprofile of the cells involved in carcinomatous progression. Histopathology 2005;46:635-41. https://doi.org/10.1111/j.1365-2559.2005.02157.x

11. Nouraei SA, Hope KL, Kelly CG, McLean NR, Soames JV. Carcinoma ex benign pleomorphic adenoma of the parotid gland. Plast Reconstr Surg 2005;116:1206-13. https://doi.org/10.1097/01. prs.0000181654.68120.0f

12. Chen AM, Garcia J, Bucci MK, Quivey JM, Eisele DW. The role of postoperative radiation therapy in carcinoma ex pleomorphic adenoma of the parotid gland. Int J Radiat Oncol Biol Phys 2007;67:138-43. https://doi.org/10.1016/j.ijrobp.2006.07.1380
13. Thompson L. World Health Organization classification of tumours: pathology and genetics of head and neck tumours. Ear Nose Throat J 2006;85:74

14. Gnepp DR. Malignant mixed tumors of the salivary glands: a review. Pathol Annu 1993;28 Pt 1:279-328.

How to cite this article: Kim JK, Kim MY, Choi SK. High grade carcinoma ex pleomorphic adenoma of parotid gland: a case report. J Korean Assoc Oral Maxillofac Surg 2020;46:348-352. https://doi. org/10.5125/jkaoms.2020.46.5.348 